\title{
Cost-effectiveness of using amyloid positron emission tomography in individuals with mild cognitive impairment
}

Young-Sil Lee ${ }^{1 \dagger}$, HyunChul Youn ${ }^{2 \dagger}$, Hyun-Ghang Jeong ${ }^{3,4^{*}}$ (D) , Tae-Jin Lee ${ }^{1,5^{*}}$, Ji Won Han ${ }^{6}$, Joon Hyuk Park ${ }^{7}$ and Ki Woong Kim ${ }^{6,8,9}$

\begin{abstract}
Background: Amyloid positron emission tomography (PET) makes it possible to diagnose Alzheimer's disease (AD) in its prodromal phase including mild cognitive impairment $(\mathrm{MCl})$. This study evaluated the cost-effectiveness of including amyloid-PET for assessing individuals with $\mathrm{MCl}$.
\end{abstract}

Methods: The target population was 60-year-old patients who were diagnosed with $\mathrm{MCl}$. We constructed a Markov model for the natural history of AD with the amyloid positivity (AP). Because amyloid-PET can detect the AP MCl state, $A D$ detection can be made faster by reducing the follow-up interval for a high-risk group. The health outcomes were evaluated in quality-adjusted life years (QALYS) and the final results of cost-effectiveness analysis were presented in the form of the Incremental Cost-Effectiveness Ratio (ICER). To handle parameter uncertainties, one-way sensitivity analyses for various variables were performed.

Results: Our model showed that amyloid-PET increased QALYs by 0.003 in individuals with MCI. The estimated additional costs for adopting amyloid-PET amounted to a total of 1250 USD per patient when compared with the cost when amyloid-PET is not adopted. The ICER was 3,71,545 USD per QALY. According to the sensitivity analyses, treatment effect of Donepezil and virtual intervention effect in $\mathrm{MCl}$ state were the most influential factors.

Conclusions: In our model, using amyloid-PET at the MCl stage was not cost-effective. Future advances in management of cognitive impairment would enhance QALYs, and consequently improve cost-effectiveness.

Keywords: Alzheimer's disease, Amyloid, Mild cognitive impairment, Cost-effectiveness, Early diagnosis

\footnotetext{
*Correspondence: jeonghg@korea.ac.kr; tjlee@snu.ac.kr

${ }^{\dagger}$ Young-Sil Lee and HyunChul Youn are contributed equally to this work

${ }^{1}$ Department of Public Health Science, Graduate School of Public

Health, Seoul National University, 1, Gwanak-ro, Gwanak-gu, Seoul 08826,

Republic of Korea

${ }^{3}$ Department of Psychiatry, Korea University Guro Hospital, Korea

University College of Medicine, 148, Gurodong-Ro, Guro-gu, Seoul 08308,

Republic of Korea

Full list of author information is available at the end of the article
}

(c) The Author(s) 2021. Open Access This article is licensed under a Creative Commons Attribution 4.0 International License, which permits use, sharing, adaptation, distribution and reproduction in any medium or format, as long as you give appropriate credit to the original author(s) and the source, provide a link to the Creative Commons licence, and indicate if changes were made. The images or other third party material in this article are included in the article's Creative Commons licence, unless indicated otherwise in a credit line to the material. If material is not included in the article's Creative Commons licence and your intended use is not permitted by statutory regulation or exceeds the permitted use, you will need to obtain permission directly from the copyright holder. To view a copy of this licence, visit http://creativecommons.org/licenses/by/4.0/. The Creative Commons Public Domain Dedication waiver (http://creativeco mmons.org/publicdomain/zero/1.0/) applies to the data made available in this article, unless otherwise stated in a credit line to the data. 


\section{Key points}

- Using amyloid-PET at the mild cognitive impairment (MCI) stage is not cost-effective based on incremental cost-effectiveness ratio and willingness-to-pay thresholds.

- According to sensitivity analyses, future advances in management of cognitive impairment could improve cost-effectiveness of amyloid-PET in individuals with MCI.

\section{Background}

According to the worldwide trends of population aging, dementia has posed a huge impact on public health in almost all countries [1]. Thus, the World Health Organization and Alzheimer's Disease International designated dementia as a global public health priority $[2,3]$. Also in South Korea, there were an estimated 6,61,707 persons with dementia (about $9.8 \%$ of people aged 65 and over) [4]. Social costs, including direct and indirect costs, were estimated at 18,200 USD per year per patient with dementia [4]. In addition, public management costs for patients with dementia were estimated at a total 12,600 million USD [4].

Alzheimer's disease (AD) is the most common cause of dementia [5] and it has a slowly progressing degenerative course [6]. Clinical experts have emphasized early diagnosis and treatment of $\mathrm{AD}$ [7] as this can enable more systematic management planning and education of patients/caregivers, and consequently lead to social costsavings $[7,8]$.

Mild cognitive impairment (MCI) has been regarded as an intermediate state between normal aging and the earliest manifestations of dementia [9]. Individuals with MCI can exhibit varying results such as reversion to normal, sustained MCI, and conversion to dementia [10]. The annual rates of conversion from MCI to dementia have been known to be around 10-15\% [10-12]. And the prevalence of $\mathrm{MCI}$ is known to be relatively high $-10 \%$ to $20 \%$ of individuals aged 65 or over [13-15]. Therefore, many previous researchers have focused on diagnosing prodromal $\mathrm{AD}$ in individuals with $\mathrm{MCI}$.

Amyloid positron emission tomography (PET) imaging, using radioactive ligands that bind to amyloid plaques, makes it possible to diagnose $\mathrm{AD}$ in its prodromal phase including MCI $[16,17]$. Many researchers have discussed the appropriate use of amyloid-PET and reported guidelines [18-21]. So far, routine use of amyloid-PET in individuals with MCI has not been generally recommended [18-21] because amyloid-PET only detects a brain histological state, not a clinical diagnosis and amyloid-lowering therapies have not been developed yet [20]. However, since amyloid-PET is helpful for early diagnosis and differential diagnosis of $\mathrm{AD}$, the clinical use of amyloid-PET has been continuously considered [1821]. In addition, many older adults want to know their disease status of cognitive disorder earlier [22]. In Korea, amyloid-PET is currently excluded from national insurance coverage, but discussions are ongoing on whether to include amyloid-PET in national insurance coverage in the future [23].

There are some previous studies that claim that amyloid-PET is cost-effective in predementia or similar states. Hornberger et al. evaluated the cost-effectiveness of adopting amyloid-PET in patients with early-stage or suspected AD in France and Spain and reported that this scanning cost-effectively increases quality-adjusted life years (QALYs) $[8,24]$. Guo et al. also showed that adopting amyloid-PET in patients with predementia and dementia is cost-effective in the United States [25]. While these studies show the cost-effectiveness of adopting amyloid-PET, they did not selectively target patients with MCI. MCI patients are in an earlier stage of disease progression than those in these previous reports, and the results on cost effectiveness of amyloid-PET in MCI can be different from those in previous studies.

Therefore, economic analyses of the implementation of amyloid-PET in patients with MCI are needed. This study evaluated the cost-effectiveness of including amyloidPET for assessing individuals with MCI. We believe that this may help determine healthcare policy, as well as dictate the indication for amyloid-PET.

\section{Methods \\ Target population}

The target population was 60-year-old patients who were diagnosed with MCI. MCI patients have identified cognitive impairment but there is uncertainty about whether they have developed AD. Therefore, there is a possibility of benefiting from additional interventions such as using amyloid-PET.

The age of patients was chosen based on previous studies and expert opinion that it is generally accepted to be earlier than the average age for the onset of $\mathrm{AD}[26,27]$. It was assumed that amyloid plaques accumulation was observable at this age.

\section{Comparator}

We set the current practice as a comparator. In the current practice, amyloid-PET is not recommended for general MCI patients [18]. We compared the current practice with the implementation of amyloid-PET for all diagnosed MCI patients. 


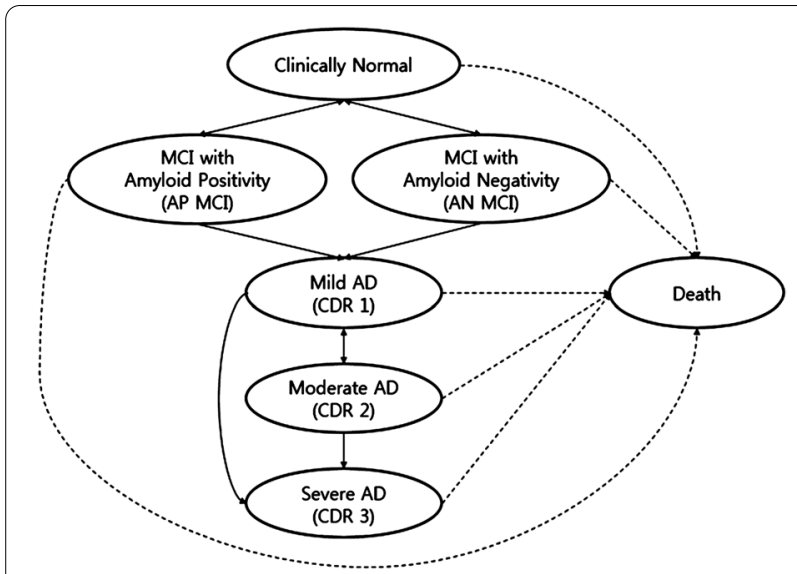

Fig. 1 Schematic representation of the Markov model

\section{Markov model}

We constructed a Markov model for the natural history of $\mathrm{AD}$ with the amyloid positivity (AP) and amyloid negativity (AN). Figure 1 is a schematic representation of this model.

\section{Model assumptions \\ Health states}

The progression after AD incidence followed Yu et al's and Neumann et al.s models [28, 29]. And the progression before AD incidence (from Clinically Normal to mild AD) followed experts' opinion. It was assumed that non-AD dementia could occur but exited from the model to focus on the effects on costs and health outcomes caused by AD.

The initial condition in all population is MCI. Without amyloid-PET, MCI patients could not be classified as AP MCI or AN MCI. MCI is clinically reversible; however, once AD occurs, it becomes clinically irreversible. Moderate $\mathrm{AD}$ can convert to mild $\mathrm{AD}$. AP MCI and AN MCI are not interchangeable and all states can lead to death.

\section{Detection of $A D$}

Moderate and severe $\mathrm{AD}$ are immediately detected because of the severity of their symptoms. However, in $\mathrm{MCI}$ and mild AD, the patients may not know their exact state. Thus, individuals in this category are only diagnosed at the time of the follow-up visit. As the follow-up interval becomes shorter, patients could know their condition more accurately. For a conservative estimation, mild $\mathrm{AD}$ was assumed to be detected 3 years after onset regardless of a follow-up.

\section{The interval of follow-up}

The interval of follow-up depends on an individual's health state. We assumed that clinically normal persons did not get a follow-up, patients with MCI got a followup every year, and $\mathrm{AD}$ patients did every three months with reference to expert opinion. AP MCI patients were assumed to get a follow-up every 3 months after they were identified by amyloid-PET. AN MCI patients were assumed to get annual follow-up visits.

\section{Treatment of $A D$}

The treatment was assumed to start from the moment AD was detected. Therefore, if a patient had not been confirmed as having $\mathrm{AD}$ by a doctor, he or she would not be treated even if they actually had mild AD. At the MCI state, any type of treatment was not assumed. AD treatment was thought to slow down the progression to a more severe cognitive status.

\section{Expected benefit of amyloid-PET}

Because amyloid-PET can detect the AP MCI state, AD detection can be made faster by reducing the follow-up interval for a high-risk group. Early detection means early treatment thereby slowing the $\mathrm{AD}$ disease progression.

\section{Parameters}

Table 1 shows the model parameters and values applied in the analyses. We used the parameters extracted from Koreans and then used overseas data if there were no appropriate Korean-specific data.

\section{Transition probabilities}

Annual transition probabilities between each health state were obtained from the Korean longitudinal study on cognitive aging and dementia (KLOSCAD) cohort and from Neumann et al. [29, 30]. When AD was detected and treatment initiated, the adjusted probabilities were applied.

\section{The excess mortality risks of AD}

MCI and mild AD were assumed to have the same mortality rates as the rates seen in the clinically normal state, which were calculated based on age-specific life tables from the Korea National Statistical Office. But moderate and severe AD were assumed to have excess mortality risks, which were calculated based on Neumann et al.s annual probability [29].

\section{The prevalence of AP MCI}

When amyloid-PET was taken in 312 patients diagnosed with MCI, 122 (39.1\%) patients were classified as AP $\mathrm{MCI}$. The results were obtained from MCI patients who 
Table 1 Model parameters and values applied in the analyses

\begin{tabular}{|c|c|c|}
\hline Parameters & Point estimates (range for sensitivity analysis) & References \\
\hline \multicolumn{3}{|l|}{ Annual transition probabilities } \\
\hline Clinically normal MCl & 0.0341 & $\mathrm{KLOSCAD}^{\mathrm{a}}$ \\
\hline $\mathrm{MCl}$ clinically normal & 0.0641 & KLOSCAD \\
\hline AN MCI mild AD & 0.0211 & KLOSCAD \\
\hline $\mathrm{MCl}$ non-AD dementia & 0.0017 & KLOSCAD \\
\hline Mild $A D$ moderate $A D$ & 0.3220 & [29] \\
\hline Mild AD severe AD & 0.0420 & [29] \\
\hline Moderate AD mild AD & 0.0430 & [29] \\
\hline Moderate AD severe AD & 0.3390 & {$[29]$} \\
\hline \multicolumn{3}{|l|}{ Excess mortality risk $\mathrm{k}^{\mathrm{b}}$} \\
\hline Moderate AD & 2.57 & [29] \\
\hline Severe AD & 7.82 & [29] \\
\hline Prevalence of amyloid positivity in $\mathrm{MCl}$ & $0.3910(0.3617,0.5556)^{c}$ & Author $^{d}$ \\
\hline Relative risk of $\mathrm{AD}$ conversion of $\mathrm{AP} \mathrm{MCl}$ & $7.95(3.53,15.20)^{c}$ & $\mathrm{SR}$ \\
\hline \multicolumn{3}{|l|}{ Diagnostic accuracy of amyloid-PET } \\
\hline Sensitivity & 0.92 & [35] \\
\hline Specificity & 1 & [35] \\
\hline \multicolumn{3}{|l|}{ Quality of life weight } \\
\hline Clinically normal (age $\geq 65$ ) & 0.874 & KNHANES \\
\hline $\mathrm{MCl}$ & 0.80 & {$[36]$} \\
\hline Mild AD & 0.43 & {$[36]$} \\
\hline Moderate AD & 0.21 & {$[36]$} \\
\hline Severe AD & 0.17 & {$[36]$} \\
\hline \multicolumn{3}{|l|}{ Medical cost per year $(\$)^{e}$} \\
\hline Clinically normal & 0 & - \\
\hline $\mathrm{MCl}$ & 794 & {$[36]$} \\
\hline Mild AD & 2113 & {$[36]$} \\
\hline Moderate AD & 1478 & {$[36]$} \\
\hline Severe AD & 1819 & {$[36]$} \\
\hline \multicolumn{3}{|l|}{ Non-medical cost per year (\$) } \\
\hline Clinically normal & 0 & - \\
\hline $\mathrm{MCl}$ & 2539 & {$[36]$} \\
\hline Mild AD & 10,956 & {$[36]$} \\
\hline Moderate AD & 11,796 & {$[36]$} \\
\hline Severe AD & 14,273 & {$[36]$} \\
\hline Amyloid PET cost (\$) & $1041(520,1561)^{f}$ & Author \\
\hline Additional follow-up cost per 1 visit (\$) & $27(14,41)^{f}$ & $\mathrm{HIRA}+[36]$ \\
\hline Treatment effect & $0.85(0.70,0.93)^{9}$ & SR \\
\hline Virtual intervention effect for AP $\mathrm{MCI}^{\text {h }}$ & $1(0.95,1)$ & Assumption \\
\hline Start age & $60(60,80)$ & - \\
\hline Discount rate & 0.05 & - \\
\hline
\end{tabular}

AD Alzheimer's disease, AN amyloid negative, AP amyloid positive, HIRA Korean Health Insurance Review \& Assessment Service, KNHANES Korea National Health and Nutrition Examination Survey, MCI Mild Cognitive Impairment, SR Systematic Review result by authors

${ }^{a}$ Korean longitudinal study on cognitive aging and dementia. The values in the table are unpublished data. For a description of the KLOSCAD cohort, see Han et al.[30]

${ }^{b}$ Neumann et al. did not directly present excessive mortality risks [29]. Authors calculated it based on their annual probabilities

'The minimum and maximum value were obtained from Doraiswamy et al. [31], Ong et al. [32], Schreiber et al. [33], and Thurfjell et al.[34]

${ }^{\mathrm{d}}$ The values derived from survey or clinical study performed with this economic evaluation study

e All costs were measured in 2017 and converted as follows: 1,130 KW to 1 USD

${ }^{f}$ The range of sensitivity analyses for cost items, $\pm 50 \%$ of the base-case value was set to the range

${ }^{9}$ The minimum and maximum value were obtained from individual studies included in the synthesis

${ }^{h}$ If the effect is 0.95 , it means that the probability of moving from AP MCI state to mild AD state will be 0.95 times 
underwent amyloid-PET at Korea University Guro Hospital or Seoul National University Bundang Hospital. Please e-mail us for more details.

\section{Relative risk of $A D$ conversion from $A P \mathrm{MCI}$}

Though the other probabilities in the model were obtained from cohort studies, there were no reliable values for AD incidence rate based on the amyloid positivity state. To solve this problem, we conducted a systematic literature review to obtain the relative risk of $\mathrm{AD}$ conversion from AP MCI when compared with the rate of conversion from AN MCI. The prospective studies that observed MCI patients, whose baseline amyloid positivity state was known over a certain period of time so as to observe the incidence of AD, were collected. Finally, four studies were selected [31-34] and the relative risk was calculated by dividing the rate of AP MCI converting to $\mathrm{AD}$ by the rate of $\mathrm{AN} \mathrm{MCI}$ converting to $\mathrm{AD}$. As a result, we found that AD occurs in AP MCI 7.95 times more than in AN MCI. We assumed that the incidence of $\mathrm{AD}$ in $\mathrm{AN} \mathrm{MCI}$ was equal to the incidence of $\mathrm{AD}$ in general MCI.

\section{Diagnostic accuracy of amyloid-PET}

The diagnostic accuracy of amyloid-PET in this study indicates its ability to distinguish between AP and AN. It is related to whether or not amyloid accumulation in the brain is higher than threshold only and is not related to the presence of dementia or MCI. We used the results obtained from an A16 phase trial, which was the only study that used autopsy to confirm amyloid accumulation in the brain [35].

\section{Health-related quality of life}

Health-related quality of life was measured using the Korean version of the EQ-5D-3L in a survey (Seoul National University IRB No. 1707/003-021) linked to this study. Participating patients were stratified by severity and the quality of life weights were also calculated by severity [36]. Severity classification followed the Clinical Dementia Rating (CDR) [37].

\section{Costs}

The costs of this study were derived from the healthcare system perspective. Direct medical costs, direct nonmedical costs, time and travel costs for both patients and caregivers, care costs including caregivers' time costs, and long-term care costs were included. Productivity costs were excluded.

All costs, except direct medical costs, were calculated from the survey described above [36]. The responses were averaged by CDR severity and adjusted as an annual cost. Direct medical costs were calculated by reviewing the hospital records and using only the costs associated with dementia.

Amyloid-PET testing costs and follow-up costs were calculated by multiplying the unit cost by the frequency of uses. There is no formal amyloid-PET unit cost because amyloid-PET is not reimbursed by National Health Insurance (NHI) in Korea. Therefore, the average cost of the three hospitals that participated in the study was applied. Follow-up cost is the sum of consultation fee, travel cost, and time cost. Consultation fee was taken from $\mathrm{NHI}$ and travel and time cost were calculated from the survey.

All costs were measured in 2017 and converted as follows: 1,130 KW to 1 USD, using the International Monetary Fund's official exchange rate [38].

\section{Treatment effects}

We used synthesis-based estimates when applying treatment effects to AD patients. Donepezil was set as the standard of treatment drug and individual literature was selected in the Cochrane review published in 2018 [28, 39]. Only those studies with the Clinician's InterviewBased Impression of Change scale (CIBIC-plus) or Clinical Global Impression of Improvement scale (CGIC) outcomes were selected to reflect the comprehensive improvement of AD symptoms. After extracting the necessary information from the selected studies, the relative risk (RR) was calculated using Review Manager 5.3 with the fixed effect model chosen based on a small number of studies and non-significance of heterogeneity test. The synthesized RR was 0.85 (95\% CI: 0.80-0.90), implying that the probability of an $\mathrm{AD}$ patient progressing to an advanced state will be lower by 0.85 times when treated with Donepezil compared to placebo.

\section{Analysis}

The analysis was initiated at age 60 and all subjects were analyzed until death. It might be better to set the time horizon as a lifetime to include all the costs and health outcomes caused by AD. The cycle length of the Markov model was set to 3 months to reflect the change in the follow-up interval and half-cycle correction was applied. We used TreeAge Pro 2019, R2 (TreeAge Software, Inc., Williamstown, MA).

The health outcomes of our study were evaluated in QALYs, which make it possible to reflect on the major disease characteristics of $\mathrm{AD}$, i.e., the declining quality of life. Both costs and health outcomes were discounted at an annual rate of $5 \%$, as recommended by Korean Health Insurance Review \& Assessment Service (HIRA) guidelines. The final results of cost-effectiveness analysis were 
presented in the form of the Incremental Cost-Effectiveness Ratio (ICER).

\section{Sensitivity analyses}

To handle parameter uncertainties, one-way sensitivity analyses for various variables were performed and presented in the form of tornadogram.

Base-case analysis assumed no treatment when a patient was in the MCI state, but for comparison with similar studies [8, 24, 25], we performed a sensitivity analysis assuming the existence of virtual interventions that could reduce the incidence of $\mathrm{AD}$ when in the $\mathrm{AP}$ MCI state. In such a case, patients identified as AP MCI via amyloid-PET would receive additional benefits.

The range of sensitivity analyses used minimum and maximum values if there were previous studies. For the cost items, $\pm 50 \%$ of the base-case value was set to the range. Exceptionally, the annual management cost, which is the sum of annual medical cost and non-medical cost, used input values of a previous study [25] to compare the

Table 2 Cost-effectiveness of amyloid-PET for MCI patients

\begin{tabular}{llllll}
\hline & Cost(\$) & $\Delta \operatorname{Cost}(\$)$ & QALYs & $\Delta$ QALYs & ICER \\
\hline No amyloid-PET & 60,037 & & 8.757 & & \\
Do amyloid-PET & 61,287 & 1250 & 8.760 & 0.003 & $3,71,545^{\text {a }}$
\end{tabular}

QALYs quality-adjusted life years, ICER Incremental Cost-Effectiveness Ratio

${ }^{\text {a }}$ This ICER is sensitive to small changes in the QALY difference caused by rounding off error result directly. The values of the previous study were used after adjusting for the inflation rate.

Written informed consent was obtained from all the participants and their legal guardian. The necessary ethical permissions were received from the Institutional Review Board at Korea University Guro Hospital (2016GR0003/2016GR0200), Jeju National University Hospital (2016-06-017), Seoul National University (1707/003-021), and Seoul National University Bundang Hospital (B-1608/360-007).

\section{Results}

Table 2 shows the result of base-case analysis. In MCI patients, the cost was $\$ 60,037$ without amyloid-PET and $\$ 61,287$ with amyloid-PET, i.e., a $\$ 1,250$ increased. QALYs were 8.757 and 8.760 , respectively, showing an increase by 0.003 with amyloid-PET. The ICER was $\$ 371,545$ per QALY.

Figure 2 shows the main results of one-way sensitivity analyses. Treatment effect of Donepezil and virtual intervention effect for AP MCI were the most influential factors. In particular, it seemed cost-effective (ICER $\$ 19,461$ per QALY) when the lowest virtual intervention effect for AP MCI (0.95) was applied. In all other cases, ICERs were larger than $\$ 160,000$ per QALY.

\section{Discussion}

Our results showed that amyloid-PET increased QALYs by 0.003 in individuals with MCI. The estimated additional costs for adopting amyloid-PET in individuals with MCI amounted to a total of 1250 USD per patient

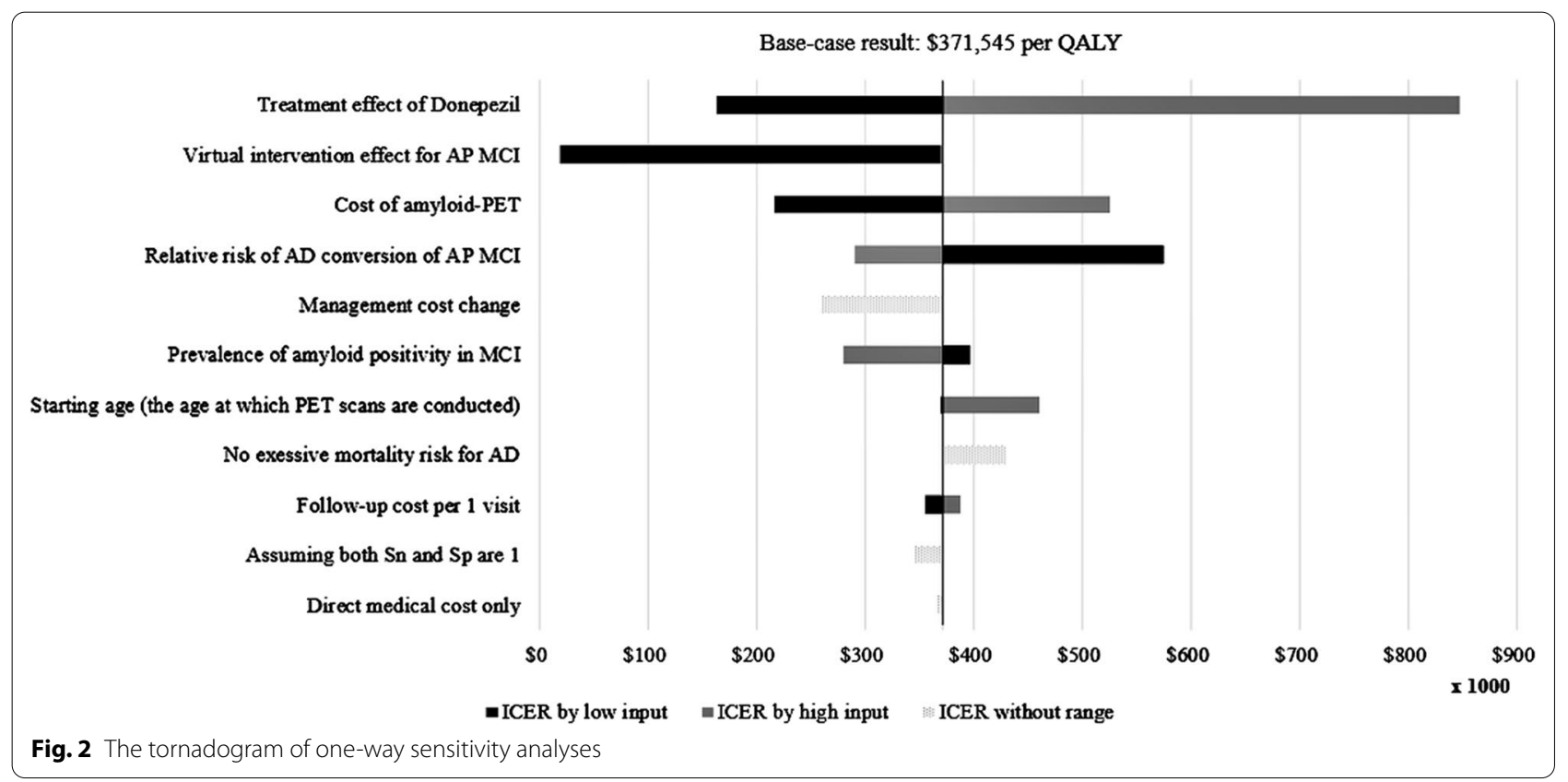


when compared with the cost when amyloid-PET is not adopted. Consequently, the ICER of our model was 3,71,545 USD per QALY. The threshold for ICER varies in countries. 30,000 EUR (i.e., 35,000 USD), 40,000 EUR (i.e., 47,000 USD), and 50,000 USD per QALY were affordable ICER in Spain, France, and in the United States studies on cost-effectiveness of adopting amyloid-PET, respectively $[8,24,25]$. In South Korea, though there is no official threshold for ICER, willingness-to-pay per QALY was estimated at 27,000 USD in 2012 [40]. Even after considering inflation, the ICER of our model is considerably higher than the willingness-to-pay per QALY in South Korea.

As far as we know, three economic evaluation studies about $18 \mathrm{~F}$ amyloid-PET have been published so far [8, 24, 25 ] and our result is the complete opposite of that of previous studies. We believe that this difference may be due to several different settings and assumptions.

First, the assumptions related to disease progression are different. Previously Spain, France, and United States studies assumed that cognitive functioning would only deteriorate into dementia from the MCI state if not treated [8,24,25]. This assumption can increase the benefits of amyloid-PET by rating the benefits of early detection highly. Unlike these studies, we assumed the possibility of reversion to clinically normal from the MCI state (0.0641). Some previous studies have reported that individuals with MCI could return to cognitively normal states. Koepsell et al. showed that $16 \%$ of subjects diagnosed with MCI reverted back to normal or nearnormal cognition approximately one year later [41]. Malek-Ahmadi conducted a meta-analysis and found an overall reversion rate of approximately $24 \%$ [42]. Our assumption reflects these previous studies.

Second, assumptions about treatment are different. In our model, it was assumed that treatment could not be started immediately, even if brain amyloid accumulation was detected in the elderly with MCI. That is, we assumed that treatment for dementia began only when the progression to dementia was detected by reflecting the policy and guideline of NHI in South Korea [43]. Time of treatment initiation in previous models of Spain and France was assumed earlier than that of our model $[8,24]$. Considering the common assumption that dementia medications have some effect in the course of cognitive decline, a delayed start of treatment in our model may have contributed in part to our high ICER of amyloid-PET.

In particular, Guo et al. assumed that virtual treatment during the predementia phase would reduce the risk of conversion by $50 \%$ among those patients with prodromal $\mathrm{AD}$ [25]. To date, the evidence for interventions to reduce the risk of conversion to dementia in predementia is very limited [44-47]. As a result of the sensitivity analysis using similar assumptions for the comparison with the previous studies, we found that the cost-effectiveness of amyloid-PET was greatly improved as in Guo et al. [25]. This implies that amyloid-PET could be a cost-effective alternative if interventions that would significantly reduce the risk of conversion from MCI to dementia were developed, but not cost-effective at the moment. In addition, previous studies have assumed that the treatments for $\mathrm{AD}$ have no effect on non-AD dementia. Actually, there are pieces of evidence that these are also effective in vascular dementia [48] or Parkinson's disease dementia [49]. Thus, the above assumption may have exaggerated the benefits of amyloid-PET.

Third, Korea has a relatively low care costs for severe $\mathrm{AD}$ than other countries. In our study, the annual care cost of severe AD was 16,092 USD (medical cost of 1,819 USD + non-medical cost of 14,273 USD), which was approximately 3,000 USD different from mild AD (13,069 USD) or moderate $\mathrm{AD}(13,274$ USD). Although the severity classification method and the cost estimation method were different, in Guo et al., the annual care cost was about 14,000 USD for mild state, 34,000 USD for moderate state, and 60,000 USD for severe state [25] and in the remaining two studies, it was assumed that the care time and cost increased rapidly with severity. The time to care for severe patient was more than twice the amount of time needed to care for mild patient $[8,24]$. If the cost difference between the severities is large, the benefit from early detection becomes bigger. Our sensitivity analysis result was consistent with this. However, when we inserted the annual management cost of the previous study in the United States, the reduced ICER was still as high as 2,60,789 USD.

There are some limitations to our analysis. First, because amyloid-PET is a relatively recent technology, some data related to it are limited. For example, there were no reliable values for the AD incidence rate based on the state of amyloid positivity; therefore, we carried out a systematic literature review and sensitivity analysis. If there was a large-scale cohort study, it would be possible to obtain a robust value and also obtain values by age.

Second, we did not include reduction in the use of other tests caused by including amyloid-PET because we believe that such an analysis would be more reflective of real-life clinical practice. We believe that amyloidPET is not yet a replacement of brain structural imaging, F-18 fluorodeoxyglucose-PET, and neuropsychological testing in real clinical practice. However, some studies have reported that amyloid-PET can be associated with reduction of other tests. Johnson et al. included reduction of other imaging and neuropsychological testing in anticipated impact of amyloid-PET [18]. Grundman et al. 
investigated potential impact of amyloid imaging in 229 patients with a history of cognitive decline and uncertain diagnosis, and reported that amyloid-PET reduced brain structural imaging by $24.4 \%$ and neuropsychological testing by $32.8 \%$ [50]. In this respect, our model may have underestimated the benefits of amyloid-PET.

Third, we eliminated non-AD dementia from our model. This setting may underestimate the benefit of amyloid-PET because amyloid-PET helps to more accurately distinguish types of dementia in patients with dementia. However, since our target population were MCI patients who had not yet developed dementia, and some of the treatments for AD patients are commonly used for patients with non-AD dementia [48, 49], the setting where amyloid-PET can more accurately diagnose the dementia type, leading to an effective treatment, poses a risk of overestimating the benefits of amyloidPET. Further studies are needed to clarify the economic benefits of amyloid-PET populations including non-AD dementia patients.

Fourth, we implemented one-way sensitivity analyses to address parameter uncertainties, which failed to consider distributional concerns or correlation between parameters. A probabilistic sensitivity analysis would be preferred in future studies.

\section{Conclusion}

This is the first study that has assessed the cost-effectiveness of adopting amyloid-PET in individuals with MCI in South Korea. According to our model, using amyloid-PET at the MCI stage is not cost-effective. Future advances in management of cognitive impairment could enhance QALYs, and consequently improve cost-effectiveness if amyloid-PET is added to manage individuals with $\mathrm{MCI}$. We believe that our findings have provided more real-life evidence to the present and future healthcare policies with regards to the addition of amyloid-PET in the management of $\mathrm{MCI}$.

\begin{abstract}
Abbreviations
AD: Alzheimer's disease; AN: Amyloid negativity; AP: Amyloid positivity; CDR: Clinical Dementia Rating; CGIC: Clinical Global Impression of Improvement scale; CIBIC-plus: Clinician's Interview-Based Impression of Change scale; HIRA: Korean Health Insurance Review \& Assessment Service; ICER: Incremental Cost-Effectiveness Ratio; KLOSCAD: Korean longitudinal study on cognitive aging and dementia; MCl: Mild cognitive impairment; NHI: National Health Insurance; PET: Positron emission tomography; QALYs: Quality-adjusted life years; RR: Risk ratio.
\end{abstract}

\section{Acknowledgements}

Not applicable.

\section{Authors' contributions}

HGJ and TJL conceived, conceptualized, and designed the study. JWH and JHP reviewed and critiqued the study protocol. HGJ, TJL, JWH, JHP, and KWK contributed to the acquisition of the data. YSL and TJL performed statistical analyses. YSL and HCY conducted literature searches and provided summaries of previous research studies. YSL and HCY drafted the manuscript. HGJ and TJL participated in reviewing the manuscript. All authors read and approved the final manuscript.

\section{Funding}

This project was supported by the Korea Health Technology R\&D Project through the Korea Health Industry Development Institute (KHIDI), funded by the Ministry of Health \& Welfare, Republic of Korea (HC15C1509 to JW Han, JH Park, TJ Lee, and HG Jeong). Additional funding came from the Korean Health Technology R\&D Project, Ministry of Health and Welfare, Republic of Korea [HI09C1379 (A092077) to KW Kim].

\section{Availability of data and materials}

The datasets used and/or analyzed during the current study are available from the corresponding authors on reasonable request.

\section{Declarations}

Ethics approval and consent to participate

Written informed consent was obtained from all the participants and their legal guardian. The necessary ethical permissions were received from the Institutional Review Board at Korea University Guro Hospital (2016GR0003/2016GR0200), Jeju National University Hospital (2016-06-017), Seoul National University (1707/003-021), and Seoul National University Bundang Hospital (B-1608/360-007).

\section{Consent for publication}

Not applicable.

\section{Competing interests}

The authors declare that they have no competing interests.

\section{Author details}

${ }^{1}$ Department of Public Health Science, Graduate School of Public Health, Seoul National University, 1, Gwanak-ro, Gwanak-gu, Seoul 08826, Republic of Korea. ${ }^{2}$ Department of Psychiatry, Soonchunhyang University Bucheon Hospital, 170 Jomaru-ro, Wonmi-gu, Bucheon 14584, Republic of Korea. ${ }^{3}$ Department of Psychiatry, Korea University Guro Hospital, Korea University College of Medicine, 148, Gurodong-Ro, Guro-gu, Seoul 08308, Republic of Korea. ${ }^{4}$ Korea University Research Institute of Mental Health, 148, Gurodong-Ro, Guro-gu, Seoul 08308, Republic of Korea. ${ }^{5}$ Institute of Health and Environment, Seoul National University, 1, Gwanak-ro, Gwanak-gu, Seoul 08826, Republic of Korea. ${ }^{6}$ Department of Neuropsychiatry, Seoul National University Bundang Hospital, 82 Gumi-ro 173beon-gil, Bundang-gu, Seongnam 13620, Republic of Korea. ${ }^{7}$ Department of Psychiatry, Jeju National University School of Medicine, Jeju National University Hospital, Aran 13 gil, Jeju-si, Jeju 63241, Republic of Korea. ${ }^{8}$ Department of Psychiatry, Seoul National University College of Medicine, 101, Daehak-ro, Jongno-gu, Seoul 03080, Republic of Korea. ${ }^{9}$ Department of Brain and Cognitive Science, Seoul National University College of Natural Sciences, 1, Gwanak-ro, Gwanak-gu, Seoul 08826, Republic of Korea.

Received: 20 January 2020 Accepted: 23 July 2021

Published online: 14 August 2021

\section{References}

1. Xu J, Qiu C. Worldwide Economic Costs and Societal Burden of Dementia. In: Perneczky R, editor. Biomarkers for Preclinical Alzheimer's Disease. Springer: New York; 2018. p. 3-13.

2. World Health Organization, Alzheimer's Disease International. Dementia: a public health priority. 3rd ed. Geneva: World Health Organization; 2012.

3. Prince M, Wimo A, Guerchet M, Ali G-C, Wu Y-T, Prina M, et al. World Alzheimer Report 2015: the global impact of dementia: an analysis of prevalence, incidence, cost and trends. London: Alzheimer's Disease International; 2015.

4. Ministry of Health and Welfare. Korean dementia observatory 2017. Ministry of Health and Welfare, Sejong; 2017. 
5. Qiu C, Kivipelto M, von Strauss E. Epidemiology of Alzheimer's disease: occurrence, determinants, and strategies toward intervention. Dialogues Clin Neurosci. 2009;11:111-28.

6. Albert MS, DeKosky ST, Dickson D, Dubois B, Feldman HH, Fox NC, et al. The diagnosis of mild cognitive impairment due to Alzheimer's disease: recommendations from the National Institute on Aging-Alzheimer's Association workgroups on diagnostic guidelines for Alzheimer's disease. Alzheimers Dement. 2011;7:270-9.

7. Weimer DL, Sager MA. Early identification and treatment of Alzheimer's disease: social and fiscal outcomes. Alzheimers Dement. 2009;5:215-26.

8. Hornberger J, Bae J, Watson I, Johnston J, Happich M. Clinical and cost implications of amyloid beta detection with amyloid beta positron emission tomography imaging in early Alzheimer's disease-the case of florbetapir. Curr Med Res Opin. 2017;33:675-85.

9. Panegyres P, Berry R, Burchell J. Early dementia screening. Diagnostics. 2016;6:6.

10. Gauthier S, Reisberg B, Zaudig M, Petersen RC, Ritchie K, Broich K, et al. Mild cognitive impairment. Lancet. 2006;367:1262-70.

11. Mitchell AJ, Shiri-Feshki M. Rate of progression of mild cognitive impairment to dementia-meta-analysis of 41 robust inception cohort studies. Acta Psychiatr Scand. 2009;119:252-65.

12. Petersen RC, Smith GE, Waring SC, Ivnik RJ, Tangalos EG, Kokmen E. Mild cognitive impairment: clinical characterization and outcome. Arch Neurol. 1999;56:303-8.

13. Plassman BL, Langa KM, Fisher GG, Heeringa SG, Weir DR, Ofstedal MB, et al. Prevalence of cognitive impairment without dementia in the United States. Ann Intern Med. 2008;148:427-34.

14. Manly JJ, Tang MX, Schupf N, Stern Y, Vonsattel JP, Mayeux R. Frequency and course of mild cognitive impairment in a multiethnic community. Ann Neurol. 2008;63:494-506.

15. Lopez OL, Jagust WJ, DeKosky ST, Becker JT, Fitzpatrick A, Dulberg C, et al. Prevalence and classification of mild cognitive impairment in the Cardiovascular Health Study Cognition Study: part 1. Arch Neurol. 2003;60:1385-9.

16. Serý $O$, Povová J, Míšek I, Pešák $L$, Janout $V$. Molecular mechanisms of neuropathological changes in Alzheimer's disease: a review. Folia Neuropathol. 2013;51:1-9.

17. Rice $L$, Bisdas S. The diagnostic value of FDG and amyloid PET in Alzheimer's disease-a systematic review. Eur J Radiol. 2017;94:16-24.

18. Johnson KA, Minoshima S, Bohnen NI, Donohoe KJ, Foster NL, Herscovitch $\mathrm{P}$, et al. Appropriate use criteria for amyloid PET: a report of the Amyloid Imaging Task Force, the Society of Nuclear Medicine and Molecular Imaging, and the Alzheimer's Association. Alzheimers Dement. 2013:9:e1-16.

19. Johnson KA, Minoshima S, Bohnen NI, Donohoe KJ, Foster NL, Herscovitch $\mathrm{P}$, et al. Update on appropriate use criteria for amyloid PET imaging: dementia experts, mild cognitive impairment, and education. Amyloid Imaging Task Force of the Alzheimer's Association and Society for Nuclear Medicine and Molecular Imaging. Alzheimers Dement. 2013;9:e106-9.

20. Laforce R, Rosa-Neto P, Soucy JP, Rabinovici GD, Dubois B, Gauthier S. Canadian Consensus Guidelines on Use of Amyloid Imaging in Canada: update and future directions from the specialized task force on amyloid imaging in Canada. Can J Neurol Sci. 2016:43:503-12.

21. Guerra UP, Nobili FM, Padovani A, Perani D, Pupi A, Sorbi S, et al. Recommendations from the Italian Interdisciplinary Working Group (AIMN, AIP, SINDEM) for the utilization of amyloid imaging in clinical practice. Neurol Sci. 2015;36:1075-81.

22. Wikler EM, Blendon RJ, Benson JM. Would you want to know? Public attitudes on early diagnostic testing for Alzheimer's disease. Alzheimers Res Ther. 2013;5:43.

23. Health Insurance Review \& Assessment Service. F-18 Florbetaben positron emission tomography. 2016. https://www.hira.or.kr/cms/policy/05/ 02/01/1349944_27059.html. Accessed 20 Aug 2019.

24. Hornberger J, Michalopoulos S, Dai M, Andrade P, Dilla T, Happich M. Cost-Effectiveness of Florbetapir-PET in Alzheimer's Disease: A Spanish Societal Perspective. J Ment Health Policy Econ. 2015;18:63-73.

25. Guo S, Getsios D, Hernandez L, Cho K, Lawler E, Altincatal A, et al. Florbetaben PET in the early diagnosis of alzheimer's disease: a discrete event simulation to explore its potential value and key data gaps. Int J Alzheimers Dis. 2012;2012:548157.

26. Novotni G, Jakimovska M, Plaseska-Karanfilska D, Tanovska N, Kuzmanovski I, Aleksovski V, et al. Evaluation of APOE genotype and vascular risk factors as prognostic and risk factors for Alzheimer's disease and their influence on age of symptoms onset. Open Access Maced J Med Sci. 2019;7:516-20.

27. Koedam EL, Lauffer , van der Vlies AE, van der Flier WM, Scheltens $P$, Pijnenburg YA. Early-versus late-onset Alzheimer's disease: more than age alone. J Alzheimers Dis. 2010;19:1401-8.

28. Yu SY, Lee TJ, Jang SH, Han JW, Kim TH, Kim KW. Cost-effectiveness of nationwide opportunistic screening program for dementia in South Korea. J Alzheimers Dis. 2015;44:195-204.

29. Neumann PJ, Araki SS, Arcelus A, Longo A, Papadopoulos G, Kosik KS et al. Measuring Alzheimer's disease progression with transition probabilities: estimates from CERAD. Neurology. 2001;57:957-64.

30. Han JW, Kim TH, Kwak KP, Kim K, Kim BJ, Kim SG, et al. Overview of the Korean Longitudinal Study on cognitive aging and dementia. Psychiatry Investig. 2018;15:767-74.

31. Doraiswamy PM, Sperling RA, Johnson K, Reiman EM, Wong TZ, Sabbagh MN, et al. Florbetapir F 18 amyloid PET and 36-month cognitive decline: a prospective multicenter study. Mol Psychiatry. 2014;19:1044-51.

32. Ong KT, Villemagne VL, Bahar-Fuchs A, Lamb F, Langdon N, Catafau AM, et al. Abeta imaging with 18F-florbetaben in prodromal Alzheimer's disease: a prospective outcome study. J Neurol Neurosurg Psychiatry. 2015;86:431-6.

33. Schreiber S, Landau SM, Fero A, Schreiber F, Jagust WJ, Alzheimer's Disease Neuroimaging Initiative. Comparison of visual and quantitative florbetapir $\mathrm{F} 18$ positron emission tomography analysis in predicting mild cognitive impairment outcomes. JAMA Neurol. 2015;72:1183-90.

34. Thurfiell L, Lotjonen J, Lundqvist R, Koikkalainen J, Soininen H, Waldemar $\mathrm{G}$, et al. Combination of biomarkers: PET [18F] flutemetamol imaging and structural MRI in dementia and mild cognitive impairment. Neurodegener Dis. 2012;10:246-9.

35. Clark CM, Pontecorvo MJ, Beach TG, Bedell BJ, Coleman RE, Doraiswamy PM, et al. Cerebral PET with florbetapir compared with neuropathology at autopsy for detection of neuritic amyloid-beta plaques: a prospective cohort study. Lancet Neurol. 2012;11:669-78.

36. Park B, Lee T-J, Lee $Y-S$, Jang S, Choi N, Jeong H-G, et al. Cost of illness and quality of life of patients and their caregivers with mild cognitive impairment or Alzheimer's disease. J Health Tech Assess. 2019;7:62-74.

37. Hughes CP, Berg L, Danziger WL, Coben LA, Martin RL. A new clinical scale for the staging of dementia. Br J Psychiatry. 1982;140:566-72.

38. World Bank. Official exchange rate (LCU per US \$, period average). 2019. https://data.worldbank.org/indicator/pa.nus.fcrf. Accessed Aug 202019.

39. Birks JS, Harvey RJ. Donepezil for dementia due to Alzheimer's disease. Cochrane Database Syst Rev. 2018;6:CD001190.

40. Ahn JH, Kim YH, Shin SJ, Park JY. Asian international collaborative study on cost-effectiveness in healthcare decision making. National Evidencebased Healthcare Collaborating Agency, Seoul; 2012.

41. Koepsell TD, Monsell SE. Reversion from mild cognitive impairment to normal or near-normal cognition: risk factors and prognosis. Neurology. 2012;79:1591-8.

42. Malek-Ahmadi M. Reversion from mild cognitive impairment to normal cognition: a meta-analysis. Alzheimer Dis Assoc Disord. 2016;30:324-30.

43. Youn $\mathrm{H}$, Jeong H-G. Pharmacotherapy for dementia. J Korean Med Assoc. 2018;61:758-64.

44. Farina N, Llewellyn D, Isaac MG, Tabet N. Vitamin E for Alzheimer's dementia and mild cognitive impairment. Cochrane Database Syst Rev. 2017:4:Cd002854.

45. McCleery J, Abraham RP, Denton DA, Rutjes AW, Chong LY, Al-Assaf AS, et al. Vitamin and mineral supplementation for preventing dementia or delaying cognitive decline in people with mild cognitive impairment. Cochrane Database Syst Rev. 2018;11:Cd011905.

46. Russ TC, Morling JR. Cholinesterase inhibitors for mild cognitive impairment. Cochrane Database Syst Rev. 2012;9:Cd009132.

47. Yue J, Dong BR, Lin X, Yang M, Wu HM, Wu T. Huperzine A for mild cognitive impairment. Cochrane Database Syst Rev. 2012;12:Cd08827.

48. Malouf R, Birks J. Donepezil for vascular cognitive impairment. Cochrane Database Syst Rev. 2004;1:Cd004395. 
49. Rolinski M, Fox C, Maidment I, McShane R. Cholinesterase inhibitors for dementia with Lewy bodies, Parkinson's disease dementia and cognitive impairment in Parkinson's disease. Cochrane Database Syst Rev. 2012;3:Cd006504

50. Grundman M, Pontecorvo MJ, Salloway SP, Doraiswamy PM, Fleisher AS, Sadowsky $\mathrm{CH}$, et al. Potential impact of amyloid imaging on diagnosis and intended management in patients with progressive cognitive decline. Alzheimer Dis Assoc Disord. 2013;27:4-15.

\section{Publisher's Note}

Springer Nature remains neutral with regard to jurisdictional claims in published maps and institutional affiliations.
Ready to submit your research? Choose BMC and benefit from:

- fast, convenient online submission

- thorough peer review by experienced researchers in your field

- rapid publication on acceptance

- support for research data, including large and complex data types

- gold Open Access which fosters wider collaboration and increased citations

- maximum visibility for your research: over $100 \mathrm{M}$ website views per year

At BMC, research is always in progress.

Learn more biomedcentral.com/submissions 